\title{
Saldo de radiação diurno em dosséis de batata como função da radiação solar global ${ }^{1}$
}

\author{
Daytime net radiation on potato canopies as a function of global solar radiation
}

\author{
Arno Bernardo Heldwein ${ }^{2}$, Ivan Carlos Maldaner ${ }^{3 *}$, Leosane Cristina Bosco ${ }^{4}$, Gustavo Trentin ${ }^{5}$, Edenir Luis \\ Grimm $^{6}$, Sidinei Zwick Radons ${ }^{7}$ e Dionéia Daiane Pitol Lucas ${ }^{8}$
}

\begin{abstract}
Resumo - Objetivou-se determinar a relação entre o saldo de radiação $(\mathrm{Rn})$ e a radiação solar global incidente (Rg) sobre dosséis de plantas de batata em diferentes épocas de cultivo e fases de desenvolvimento para a geração de modelos lineares que representem essa relação. Os experimentos foram conduzidos na área experimental da Universidade Federal de Santa Maria, RS, nos anos de 2004 a 2007. O Rn foi medido acima do dossel de plantas de seis experimentos de batata e a Rg em uma estação meteorológica automática distante 30 a $80 \mathrm{~m}$ dos experimentos. Para fins de cálculo, foram efetuadas as somas do período diurno, de Rn e de Rg, obtendo-se a relação entre Rn e Rg para cada dia. Também foi estimado o índice de área foliar das plantas. Foram obtidos modelos com elevado coeficiente de determinação e baixa raiz do quadrado médio do erro no teste entre valores independentes medidos e estimados, indicando boa precisão para a estimativa do saldo de radiação em dosséis de batata, em função da radiação solar global, independentemente da época do ano. A função linear geral obtida com dados de diferentes anos, épocas de cultivo e genótipos não foi sensível ao índice de área foliar, resultando em: $\mathrm{Rn}=0,6410 \mathrm{Rg}\left(\mathrm{R}^{2}=0,976\right)$, que no teste apresentou $\mathrm{RQME}=0,75 \mathrm{MJ} \mathrm{m}^{-2} \mathrm{dia}^{-1}$. Conclui-se que o $\mathrm{Rn}$ pode ser estimado por meio da Rg medida nas estações automáticas com precisão suficiente para fins de modelagem.
\end{abstract}

Palavras-chave - Solanum tuberosum. Radiação disponível. Dossel de plantas. Saldo radiômetros.

\begin{abstract}
The objective of this work was to determine the relationship between net radiation (Rn) and incident solar radiation $(\mathrm{Rg})$ in potato canopy at six different cultivation periods and stages of development in order to generate linear models that describe this relationship. The experiments were conducted in the experimental area of University of Santa Maria, RS, in the years of 2004 to 2007. Rn was measured by net radiometers in six experiments and Rg by automatic weather station, situated 30 to $80 \mathrm{~m}$ from the experiments. For purposes of calculation, were performed daily sums of Rn and Rg. Through these, it was calculated the $\mathrm{Rn} / \mathrm{Rg}$ ratio for each day. There was obtained a good relationship between changes in $\mathrm{Rn}$ and $\mathrm{Rg}$. This relationship was confirmed in the regression analysis, obtaining models with high correlation coefficient, indicating precisely to estimate net radiation in potato canopies as a function of incident solar radiation $(\mathrm{Rg})$, irrespective of season. The function general linear obtained with data from different years, growing seasons and genotypes was not sensitive to leaf area index, resulting in: $\mathrm{Rg} \mathrm{Rn}=0.6410\left(\mathrm{R}^{2}=0.976\right)$, that in the test showed $\mathrm{RQME}=0.75 \mathrm{MJ} \mathrm{m}^{-2} \mathrm{dia}^{-1}$. The diurnal energy flux density of net radiation can be estimated through using the flux density of global solar radiation measured in automatic stations with sufficient accuracy for modeling.
\end{abstract}

Key words - Solanum tuberosum. Radiation availability. Net radiometers. Plant canopy.

\footnotetext{
* Autor para correspondência

${ }^{1}$ Recebido para publicação em 22/07/2010; aprovado em 10/05/2011

Pesquisa financiada pela CAPES e CNPq

${ }^{2}$ Departamento de Fitotecnia, Universidade Federal de Santa Maria-UFSM, Santa Maria-RS, Brasil, 97.105 900, heldweinab@smail.ufsm.br

${ }^{3}$ Instituto Federal Farroupilha, Campus São Vicente do Sul, São Vicente do Sul-RS, Brasil, 97.420-000, ivan_maldaner@yahoo.com.br

${ }^{4}$ Bolsista CNPq, programa de Pós-Graduação em Fitotecnia, Universidade Federal do Rio Grande do Sul-UFRGS, Porto Alegre-RS, Brasil, 91.540 000

${ }_{5}^{5}$ Pesquisador Embrapa Pecuária Sul,, Bagé-RS, Brasil, 96.401-970, gustavo.trentin@cppsul.embrapa.br

${ }^{6}$ Instituto Federal Farroupilha-Campus Alegrete, Passo Novo, Alegrete-RS, Brasil, 97.555-000, edenirgrimm@yahoo.com.br

${ }^{7}$ Universidade Federal da Fronteira Sul- Campi Cerro Largo, Cerro Largo-RS, Brasil, 97.900-000, sidineiradons@yahoo.com.br

${ }^{8}$ Bolsista CNPq, programa de Pós-Graduação em Agronomia, Universidade Federal de Santa Maria, Santa Maria-RS, Brasil, dio.pitol@gmail.com
} 


\section{Introdução}

A batateira (Solanum tuberosum L.) é uma cultura de grande importância agrícola, alimentar e econômica. $\mathrm{Na}$ safra de 2007 foram cultivados aproximadamente 24 mil hectares com batata no RS e cerca de 150 mil hectares no Brasil, totalizando a produção nacional em 3,38 milhões de toneladas (IBGE, 2009).

Nos agroecossistemas a atividade fotossintética das plantas resulta na conversão da radiação solar global incidente ( $\mathrm{Rg}$ ) em energia química (HELDWEIN et al., 2009), sendo parte importante de modelos que estimam o acúmulo de biomassa pelas plantas (ABRAHA; SAVAGE, 2008). Bisognin et al. (2008), verificaram que a Rg é a variável do ambiente que determina diferenças no rendimento de tubérculos nos cultivos de primavera e outono para o Rio Grande do Sul. Além disso, a Rg é a principal componente do saldo de radiação (Rn), a qual fornece energia para os processos de evapotranspiração, aquecimento e resfriamento do ar e do solo em um cultivo (MONTEITH, 1994; PEZZOPANE; PEDRO JÚNIOR, 2003). Todavia, para realizar o balanço de energia de um cultivo é necessário conhecer o valor de Rn (MONTEITH; UNSWORTH, 1990). É imprescindível para caracterizar o microclima do dossel de plantas e estimar a evapotranspiração (DANTAS et al., 2003; MONTEITH; UNSWORTH, 1990).

A mensuração do saldo de radiação em dosséis de plantas é onerosa e difícil (SAMANI et al., 2007). A medição de todos os componentes do balanço de radiação é outra maneira de obter o Rn, sendo que nem sempre é possível, devido à falta de equipamentos na área de cultivo e nas estações meteorológicas (SENTELHAS; NASCIMENTO, 2003). Assim, muitos autores recorreram aos dados de Rg para estimar o Rn em áreas cultivadas, como por exemplo, com soja (AZEVEDO et al., 1990), feijão caupi (LIMA et al., 2005), videira (PEZZOPANE; PEDRO JÚNIOR, 2003) e café (PEZZOPANE et al., 2005), o que torna sua determinação mais simples e, principalmente, aplicável em sistemas operacionais, nos quais conta-se apenas com medições das estações automáticas instaladas em condições padronizadas.

Existe excelente dependência linear entre o Rn e $\mathrm{Rg}$, variando os coeficientes de determinação em função da época do ano (SENTELHAS; NASCIMENTO, 2003). Na Índia, Tyagi et al. (2000) verificaram que ao longo de vários ciclos de desenvolvimento do arroz e do girassol, o saldo de radiação representou 67 e $57 \%$ da $\mathrm{Rg}$, respectivamente, enquanto que para grama batatais e capim tanzânia o Rn correspondeu, respectivamente, a 53 e 54\% da Rg (SILVA et al., 2007). Já Fietz e Fisch (2009), concluíram que $43 \%$ da $\operatorname{Rg}$ permaneceu na superfície de referência na forma de Rn. Para feijão caupi essa relação é de $61 \%$ (NEVES et al., 2008) a 78\% (LIMA et al., 2005) e para banana é de $63 \%$ (TEIXEIRA, 2001). No entanto, não foram encontrados estudos específicos com relação à estimativa do $\mathrm{Rn}$ na cultura da batata, o que permitiria obter estimativas mais precisas de evapotranspiração (SAMANI et al., 2007; IRMAK et al., 2010) e da dotação e turno de rega para essa cultura na região de estudo.

Nesse contexto, esse trabalho teve como objetivo determinar a relação entre o Rn sobre dosséis de plantas de batata em diferentes épocas de cultivo e fases de desenvolvimento e a $\mathrm{Rg}$, obtendo modelos lineares que representem essa relação.

\section{Material e métodos}

Os experimentos foram conduzidos junto à sede do Departamento de Fitotecnia da Universidade Federal

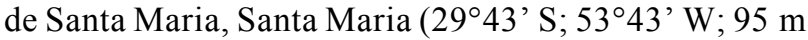
a.n.m.), localizada no centro da região fisiográfica da Depressão Central do Estado do Rio Grande do Sul (RS). O solo do local, pertencente à unidade de mapeamento São Pedro, é classificado como ARGISSOLO VERMELHO Distrófico arênico (EMBRAPA, 2006).

O clima local, segundo a classificação climática de Köppen, pertence ao tipo Cfa, subtropical úmido, com verões quentes e sem estação seca definida. Nos meses de abril a outubro, predominam os excessos hídricos, enquanto nos meses de novembro a fevereiro, as deficiências não são raras (HELDWEIN et al., 2010).

As medidas de $\mathrm{Rn}$ foram realizadas durante os períodos de "final de inverno-primavera" (safra) de 2004 e 2006, "primavera-verão" de 2005 e de "final de verãooutono" (safrinha) de 2004; 2005; 2006 e 2007, no centro de áreas de cultivo de no mínimo $960 \mathrm{~m}^{2}$, utilizando os genótipos de batata Asterix e Macaca. Os plantios foram realizados em 23/07/2004, 26/10/2005 e 03/09/2006 nos cultivos de safra e 05/03/2004, 17/03/2005 20/03/2006, e $15 / 03 / 2007$ nos cultivos de safrinha, no espaçamento $0,8 \mathrm{~m}$ entre fileiras e de $0,3 \mathrm{~m}$ entre batatas-semente na fileira. $\mathrm{O}$ manejo da cultura seguiu as recomendações técnicas para o cultivo da batata no RS (BISOGNIN, 1996). Os dados de $\mathrm{Rg}$ foram medidos com piranômetro modelo CM6b, marca Kipp \& Zonen Delft na estação meteorológica automática do Instituto Nacional de Meteorologia, distante 30 a $80 \mathrm{~m}$ dos experimentos. O Rn sobre o dossel das plantas de batata foi medido com o auxílio de dois saldo radiômetros não ventilados, marca Delta $\mathrm{T}$, modelo 8110 , instalados a $1,0 \mathrm{~m}$ de altura do solo sobre as plantas em uma fileira de plantio. Os saldo radiômetros medem o Rn pela diferença entre o que é medido na face superior ( $\operatorname{Rg}$ e radiação de onda longa incidentes) e na 
face inferior do equipamento ( $\mathrm{Rg}$ refletida + radiação de onda longa emitida pela superfície). Esses equipamentos foram conectados a um registrador eletrônico de dados (datalogger marca ELE, modelo MM900) e semanalmente substituiu-se a sílica gel para evitar a condensação de água no interior da cúpula dos sensores. As medidas foram realizadas a partir da emergência até a colheita da cultura, com a frequência de 1,0 segundo e os valores armazenados a intervalos de 10 minutos. Para fins de cálculo, foram efetuadas as integrações dos totais de $\mathrm{Rn}$ e $\mathrm{Rg}$ do período diurno das 9 às 16 horas, obtendo-se também a relação entre essas variáveis $\left(\mathrm{Rn}^{*} \mathrm{Rg}^{-1}\right)$ para cada dia. Foram utilizados somente os valores das 09 às $16 \mathrm{~h}$ em virtude de que nos períodos anteriores às 9 horas da manhã e após as 16 horas são comuns valores negativos de $\mathrm{Rn}$, principalmente nos cultivos de safrinha, o que resultaria em uma soma errônea dos valores.

A avaliação dos estádios fenológicos foi realizada durante todo o período de cultivo segundo Oliveira (2000). A data da emergência (EM) foi considerado o dia em que $50 \%$ das plantas na parcela estavam visíveis acima do solo. O início da tuberização (IT) foi determinado a partir dos 21 DAE coletando-se diariamente 2 plantas em cada uma das oito parcelas de $16 \mathrm{~m}^{2}$ de cada clone da área central dos experimentos, sendo considerada a data de IT quando $50 \%$ das plantas amostradas apresentassem pelo menos um tubérculo com 1,0 cm de diâmetro (OLIVEIRA, 2000). A data do ponto de colheita (CO) foi considerada quando $100 \%$ das plantas na parcela completaram o estágio de maturação, conforme escala de desenvolvimento da batata apresentada por Heldwein et al. (2009). Também foram medidos o comprimento e a largura das folhas para estimar a área foliar (AF) com a equação exponencial $\mathrm{AF}=0,535$ $\left(C^{*} \mathrm{~L}\right)^{0,9592}$, e, após sua integração por planta, se obteve o índice de área foliar (IAF) de cada cultivo.

A análise dos resultados foi realizada considerando todos os dados dos anos de cultivo reunidos, bem como separando-se duas épocas de plantio (final de invernoprimavera e outono), dois subperíodos de desenvolvimento (antes da tuberização e após), dois genótipos (Asterix e Macaca) e duas condições de umidade da camada superficial do solo (úmido e seco) para cada ano de cultivo. Na diferenciação das condições de solo úmido ou seco, utilizou-se como critério uma fração de água disponível de 40\% (FAD =0,40), estimada de $10 \mathrm{~mm}$, na camada superficial do solo (f) $(0-5 \mathrm{~cm})$, assumindo-se $\mathrm{f}=10 \mathrm{~mm}$ como valor máximo. Foram considerados com solo úmido os dias subsequentes às chuvas nos quais a evapotranspiração potencial (ETP) acumulada, estimanda pelo método de Penman-Monteith não superou $10 \mathrm{~mm}$. Os demais dias foram classificados como dias com superfície de solo seco. Assumiu-se a condição de contorno de que sob condições de superfície do solo úmido após chuva a evapotranspiração da cultura da batata (ETc) é similar a $\mathrm{ETP}(\mathrm{ETc} \approx \mathrm{ETP})$, pois conforme resultados experimentais de Kashiap e Panda (2001), nessas condições, decorrentes da irrigação o valor do coeficiente de cultura $(\mathrm{Kc})$ para a batata se aproxima de um $(\mathrm{Kc} \approx 1)$.

Para a época de final de inverno-primavera foram utilizados os dados dos anos de 2004 para a geração dos modelos e os dados de 2006 para a validação dos modelos. $\mathrm{Na}$ geração dos modelos para a época de outono foram utilizados os dados de 2004, 2005 e 2006, para a respectiva validação, os dados de 2007. A estatística utilizada para a avaliação do desempenho (validação) dos modelos foi principalmente a raiz quadrada do quadrado médio do erro (RQME), utilizando a equação 1 (COSTA et al., 2010):

$\mathrm{RQME}=\left(\Sigma\left(\mathrm{s}_{\mathrm{i}}-\mathrm{o}_{\mathrm{i}}\right)^{2} / \mathrm{N}\right)^{0,5}$

em que "s" é o valor estimado, "o" é o valor observado e $\mathrm{N}$ é o número de observações utilizado para a validação. Também foi considerado o coeficiente de determinação ajustado $\left(\mathrm{r}^{2}\right)$ da regressão entre os valores medidos (o) e estimados (s) pelo modelo. Os coeficientes linear e angular do teste do modelo servem como parâmetro para estimar os erros. Complementando a análise dos erros no teste dos modelos, considerou-se também o índice de exatidão (d), também denominado de índice de Willmott, conforme Arraes et al. (2009):

$$
d=1-\left[\frac{\sum(E-O)^{2}}{\sum(|E-\bar{O}|+|O-\bar{O}|)^{2}}\right]
$$

em que, E e O são os valores estimados e observados, respectivamente, e $\overline{\mathrm{O}}$ é a média dos valores observados.

\section{Resultados e discussão}

Nos cultivos de final de inverno-primavera (FI-P) os valores de $\mathrm{Rg}$ e de $\mathrm{Rn}$ apresentaram tendência de aumento ao longo do ciclo da cultura (FIG. 1A e 1C), exceto no final do período experimental de 2005 (FIG. 1B), (a partir de janeiro de 2006), em que o plantio foi atrasado para o final de outubro devido a problemas de emergência das plantas no plantio em setembro (dados não apresentados). Para os cultivos de final de verão-outono (FV-O) ocorreu tendência contrária (FIG. 1D, 1E e 1F). No cultivo de FI-P foram observados valores de radiação solar global mínimo e máximo de 0,62 e 25,05 $\mathrm{MJ} \mathrm{m}^{-2} \mathrm{dia}^{-1}$, respectivamente. Para o cultivo de FV-O o valor mínimo de radiação solar global foi de 0,51 e máximo de $18,14 \mathrm{MJ} \mathrm{m}^{-2} \mathrm{dia}^{-1}$, 

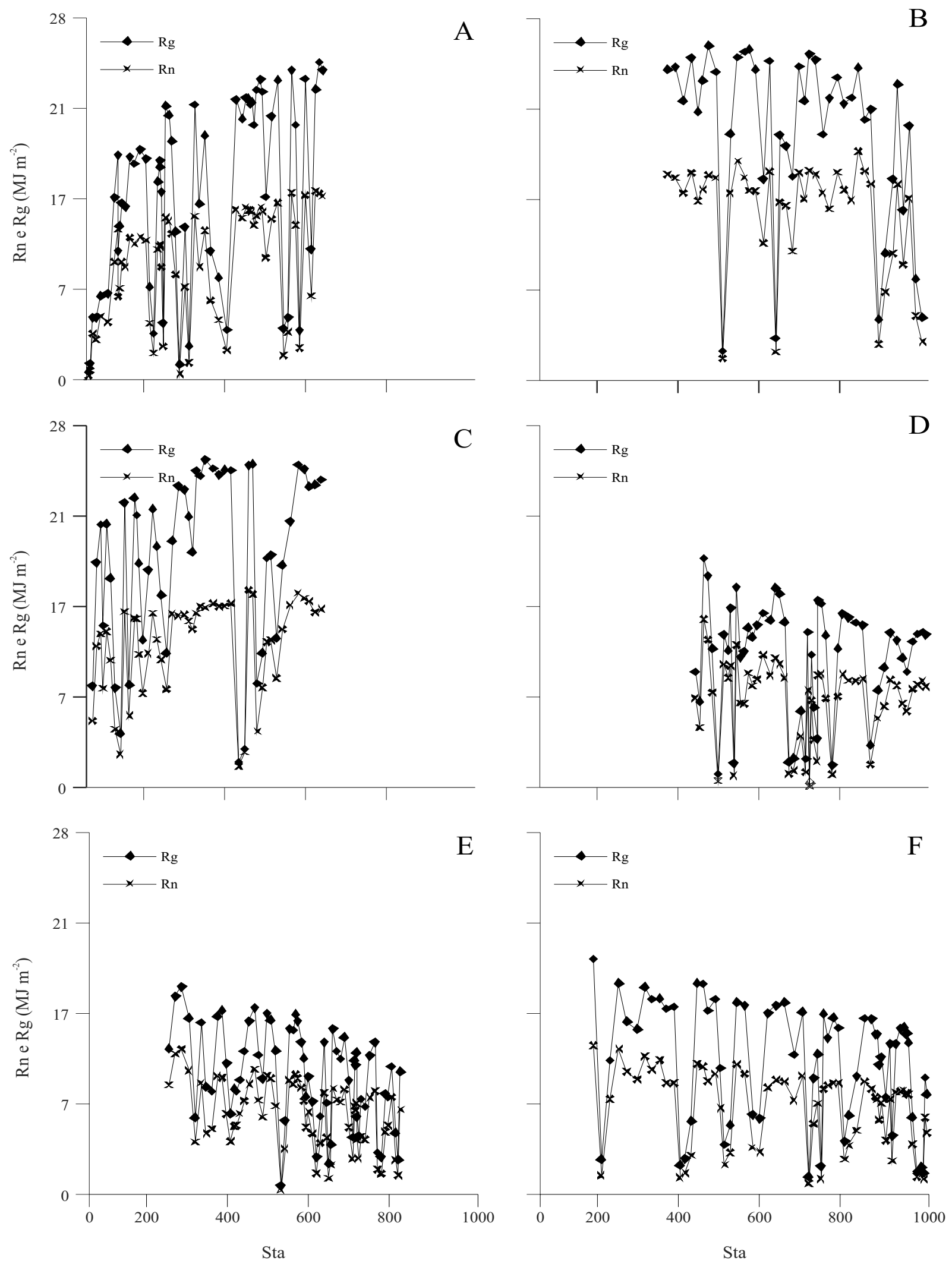

Figura 1 - Saldo de radiação $(\mathrm{Rn})$ e radiação solar global incidente $(\mathrm{Rg})$ em cultivos de batata em função da soma térmica acumulada (STa) após a emergência das plantas, nos períodos de (A) primavera de 2004 e (C) 2006, (B) primavera-verão de 2005 e (D) outono de 2005, (E) 2006 e (F) 2007, em Santa Maria, RS 
esses valores são próximos dos observados por outros autores para esta região nas mesmas épocas de cultivo (BISOGNIN et al., 2008). Essas tendências se devem às respectivas épocas do ano em que foram realizados esses experimentos. Durante o outono, no hemisfério sul o fotoperíodo decresce e o ângulo zenital dos raios solares aumenta gradativamente, o que determina uma menor incidência de energia solar na superfície à medida que se aproxima o solstício de inverno.

Nesse estudo observou-se uma boa associação entre as variações de $\mathrm{Rn} \mathrm{Rg}^{-1}$ ao longo do ciclo (FIG. 1), da ordem de 0,60 a 0,70 (FIG. 2 e TAB. 1), concordando com resultados obtidos para feijão caupi, videira, café, banana e arroz (NEVES et al., 2008; PEZZOPANE; PEDRO JÚNIOR, 2003; PEZZOPANE et al., 2005; TEIXEIRA, 2001; TYAGI et al., 2000), ou sendo menor do que o obtido para soja e feijão caupi (AZEVEDO et al., 1990; LIMA et al., 2005). Possivelmente a diferença decorra da arquitetura das plantas, grau de cobertura do solo e das características biofísicas de cada espécie, além do que no presente trabalho foi considerado o período diurno das 9 às 16 horas.

Para o conjunto de todos os dados foi obtido um coeficiente angular de 0,6410 (modelo 1) (TAB. 1), significando que as perdas de energia por processos de radiação envolvendo a reflexão da $\operatorname{Rg}$ e o saldo de radiação de onda longa (infravermelha) são de aproximadamente $35,9 \%$ da $\mathrm{Rg}$. A obtenção desse modelo, independentemente da época do ano, do genótipo utilizado, do estágio de desenvolvimento e da condição de umidade na camada superficial do solo, apresentou coeficientes de determinação superiores a 0,97 e erro inferior a $0,75 \mathrm{MJ} \mathrm{m}^{-2} \mathrm{dia}^{-1}$ (TAB. 1).

A relação $R n R^{-1}$ apresentou variação com a época do ano em que as medidas foram realizadas. No período de FI-P (safra) a relação $\mathrm{Rn} \mathrm{Rg}^{-1}$ foi menor do que nos experimentos realizados a partir de fevereiro (TAB. 1). Para a safra os coeficientes angulares encontrados nos modelos foram menores do que para o período de FV-O, considerado como safrinha no RS (TAB. 1e FIG. 2). Assim, inferese que na safra a quantidade relativa de energia radiante que permanece nos dosséis de batata é menor do que nos cultivos de safrinha. Essa diferença pode ser decorrente da conjugação de vários componentes do microambiente, principalmente, predominância de condições de superfície do solo seca e/ou mais recoberta por área foliar, resultando em maior refletividade, menor Rn e menor relação $\mathrm{Rn} \mathrm{Rg}^{-1}$ (MONTEITH; UNSWORTH, 1990). Em café a pleno sol e consorciado Pezzopane et al. (2005) também encontraram variação sazonal dos valores da relação $\mathrm{Rn} \mathrm{Rg}^{-1}$, obtendo valores de 0,34 em julho e 0,62 em janeiro em café a

Tabela 1- Modelos para estimar o saldo de radiação (Rn) sobre dosséis de batata em função da radiação solar global incidente (Rg) e respectivos coeficientes de determinação na geração e teste do modelo e coeficiente linear (a), angular (b) e raiz quadrada do quadrado médio do erro (RQME) entre valores observados e estimados

\begin{tabular}{cccccccccc}
\hline Abrangência & & & & \multicolumn{9}{c}{ Teste modelo } & Época / \\
\cline { 6 - 8 } dos dados & $\mathrm{N}^{\circ}$ & Modelo* & $\mathrm{R}^{2}$ & $\mathrm{a}$ & $\mathrm{b}$ & $\mathrm{r}^{2}$ & $\mathrm{RQME}$ & $\mathrm{d}$ & condição \\
\hline \multirow{3}{*}{ Todo ciclo } & 1 & $\mathrm{Rn}=0,6410 \mathrm{Rg}$ & 0,976 & $-0,23$ & 1,062 & 0,977 & 0,75 & 0,992 & Geral \\
& 2 & $\mathrm{Rn}=0,6631 \mathrm{Rg}$ & 0,972 & 0,29 & 1,009 & 0,979 & 0,55 & 0,991 & FV-O \\
& 3 & $\mathrm{Rn}=0,6120 \mathrm{Rg}$ & 0,989 & $-0,85$ & 1,074 & 0,965 & 0,80 & 0,989 & FI-P \\
\hline \multirow{3}{*}{ Antes do IT } & 4 & $\mathrm{Rn}=0,6779 \mathrm{Rg}$ & 0,967 & $-0,09$ & 1,081 & 0,968 & 1,20 & 0,981 & Geral \\
& 5 & $\mathrm{Rn}=0,6904 \mathrm{Rg}$ & 0,956 & 0,40 & 1,007 & 0,954 & 0,73 & 0,990 & FV-O \\
& 6 & $\mathrm{Rn}=0,6485 \mathrm{Rg}$ & 0,992 & $-0,16$ & 1,084 & 0,995 & 0,69 & 0,991 & FI-P \\
\hline \multirow{3}{*}{ Após o IT } & 7 & $\mathrm{Rn}=0,6336 \mathrm{Rg}$ & 0,980 & $-0,24$ & 1,056 & 0,979 & 0,72 & 0,993 & Geral \\
& 8 & $\mathrm{Rn}=0,6562 \mathrm{Rg}$ & 0,977 & 0,19 & 1,026 & 0,984 & 0,50 & 0,992 & FV-O \\
& 9 & $\mathrm{Rn}=0,6071 \mathrm{Rg}$ & 0,991 & $-1,23$ & 1,093 & 0,958 & 0,87 & 0,986 & FI-P \\
\hline Todo ciclo & 10 & $\mathrm{Rn}=0,6505 \mathrm{Rg}$ & 0,973 & 0,03 & 0,964 & 0,987 & 0,51 & 0,996 & G-SU \\
Todo ciclo & 11 & $\mathrm{Rn}=0,6381 \mathrm{Rg}$ & 0,964 & $-0,53$ & 1,090 & 0,965 & 0,83 & 0,986 & G-SS \\
\hline
\end{tabular}

* Modelo 1= modelo geral obtido com todos os dados de primavera e outono até o outono de 2006 e teste com os dados de final de invernoprimavera (FI-P) de 2006 e final de verão-outono (FV-O) de 2007; 2 = modelo obtido com os dados do outono de 2004 , 2005 e 2006 e teste com os dados do outono de 2007; 3 = modelo obtido com os dados da primavera de 2004 e respectivo teste com dados de $2006 ; 4=$ modelo geral até o início da tuberização (IT); $5=$ modelo antes do IT para o outono; $6=$ modelo antes do IT para a primavera; $7=$ modelo geral após o IT; $8=$ modelo após o IT para o outono; $9=$ modelo após o IT para a primavera; $10=$ modelo com todos os dados para o solo úmido (G-SU); 11 = modelo com todos os dados para superfície de solo seco (G-SS) 

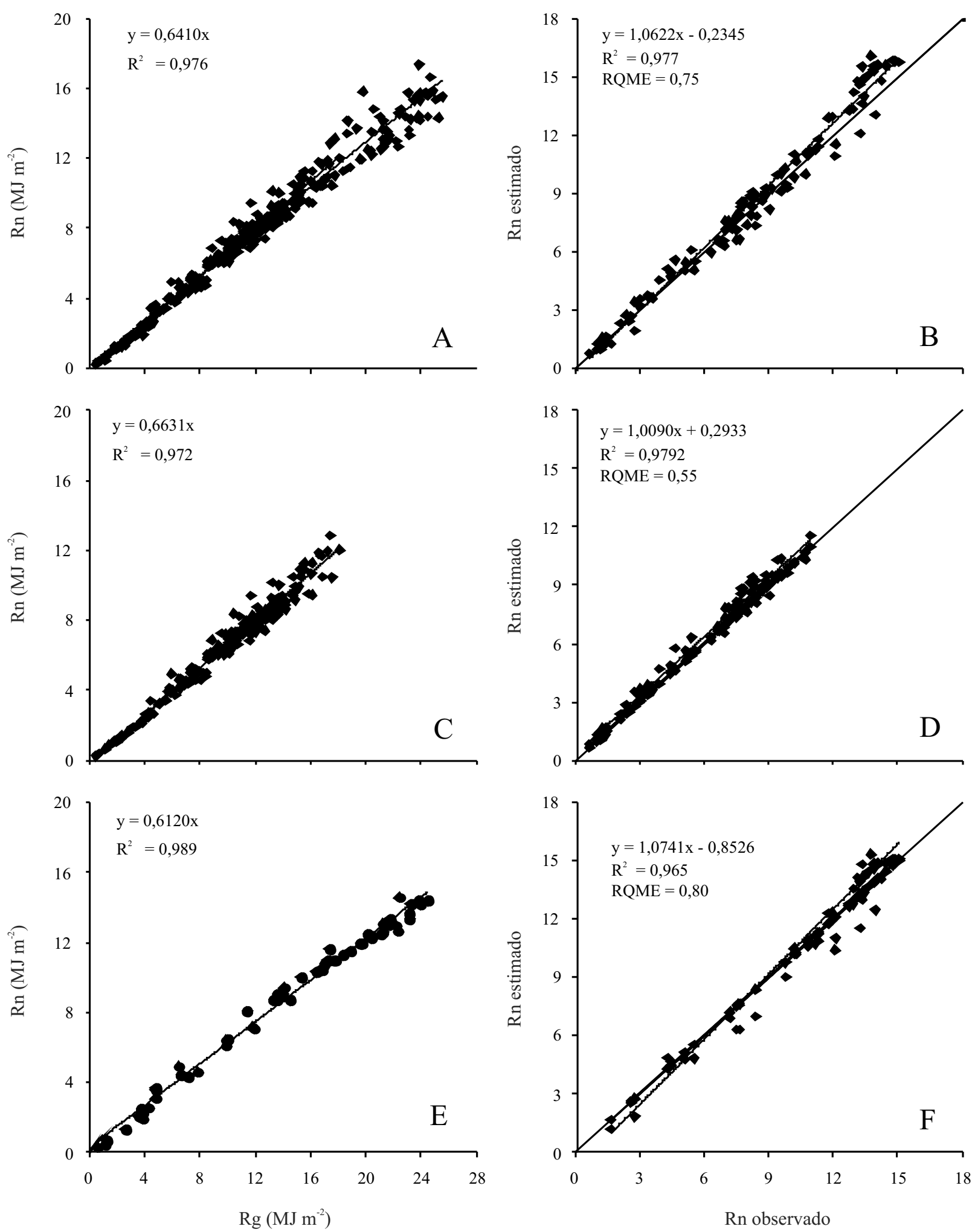

Figura 2 - Modelos de regressão linear (A) geral, (C) para outono e (E) primavera e respectivos resultados do teste entre valores estimados e observados (B geral, D outono e F primavera), entre a radiação solar global e o saldo de radiação sobre dosséis de batata, em Santa Maria, RS 
pleno sol e de 0,35 em julho e de 0,68 em novembro em área de café consorciado com bananeiras. Os menores valores determinados no período de maio a agosto foram atribuídos a menor duração do dia, com conseqüente menor valor diário de $\mathrm{Rg}$ e a um saldo de radiação de onda longa mais negativo, não havendo referência ao efeito do IAF e da umidade no solo. Essa atribuição de causa não se justifica para os atuais resultados com batata, pois nos períodos de FV-O e de FI-P a média da duração do dia foi semelhante.

Ao separar os dados de dois subperíodos do desenvolvimento, antes e após o início da tuberização, para ver se há efeito do grau de cobertura do solo, foram obtidas regressões que seguiram a mesma tendência por época, mas diferiram por subperíodo de desenvolvimento. Verificou-se que antes do IT a relação $\mathrm{Rn} \mathrm{Rg}^{-1}$ é maior do que após o IT (TAB. 1). Assim, evidencia-se o efeito do menor índice de área foliar antes do IT na relação $\mathrm{Rn} \mathrm{Rg}{ }^{-1}$, pois a superfície do solo exposto, principalmente quando úmida, tem menor refletância à $\mathrm{Rg}$ do que folhas (MONTEITH; UNSWORTH, 1990). Além disso, quanto maior o IAF, maior é a interceptação da radiação solar, conforme modelo apresentado em Heldwein et al. (2009). No entanto, considerando que as médias do IAF máximo após o IT foram 9 a 30\% maiores nos cultivos de FI-P, essa seria a principal resposta sazonal da espécie para

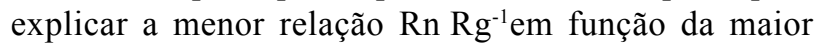
reflectância das folhas em relação ao solo exposto. Para o genótipo Asterix essa tendência foi confirmada (FIG. 3), obtendo-se a equação: $\mathrm{Rn} \mathrm{Rg}^{-1}=-0,0734$ IAF $+0,795$, com $R^{2}=0,945$, e para o genótipo Macaca, de hábito mais prostrado e, após o IT, com maior exposição do solo no camalhão resultante da amontoa, não houve relação com o IAF.

Ao comparar os modelos para solo úmido e para solo seco, é possível visualizar que a relação $\mathrm{Rn} \mathrm{Rg}^{-1}$ é pouco afetada pela condição de umidade da camada superficial do solo (TAB. 1). Com solo seco a relação $\mathrm{Rn} \mathrm{Rg}^{-1}$ obtida no modelo foi aproximadamente 1,2\% menor do que com solo úmido.

O solo seco pode apresentar uma variação de albedo entre $8 \%$ e $40 \%$ e o solo úmido entre $4 \%$ e $20 \%$ (JACOBS; PUL, 1990). Esta diminuição com a umidade é explicada pelo fato de que o albedo da água é menor do que do solo seco. Além disso, o albedo de solos completamente secos é aproximadamente 1,8 vezes maior do que em solos úmidos e diminui mais drasticamente quando o conteúdo de umidade aumenta de 1 para 15-20\% (MONTEITH; UNSWORTH, 1990). Solos secos também se aquecem mais na superfície, o que pode contribuir para aumentar a emissão de radiação. Conforme a lei de Stefan-Boltzmann uma diferença de temperatura de $2{ }^{\circ} \mathrm{C}$ na superfície do solo resulta em uma diferença de emissão de energia da

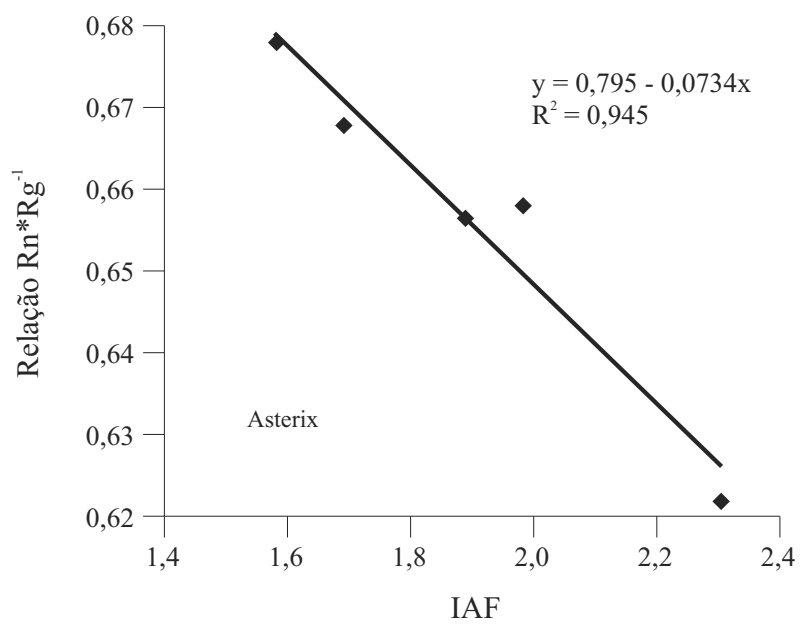

Figura 3 - Média da relação entre o saldo de radiação e a radiação solar global $\left(R n \mathrm{Rg}^{-1}\right)$ em função do índice de área foliar médio do ciclo (IAF) para o genótipo de batata Asterix em três cultivos realizados na época do outono (safrinha) e dois na primavera (safra), em Santa Maria, RS

ordem de $11 \mathrm{~W} \mathrm{~m}^{-2}$ entre 15 a $27^{\circ} \mathrm{C}$. No entanto, as duas equações obtidas nesse trabalho não representam essa diferença, devendo haver compensação por outros fatores, principalmente pela cobertura foliar. De qualquer forma, para fins práticos operacionais o modelo geral pode ser utilizado para estimar Rn tanto para dias com superfície do solo relativamente seca quanto para solo úmido, não havendo necessidade de usar outros modelos.

Em relação aos genótipos, a diferença entre os modelos gerados também não foi expressiva. Para o genótipo Macaca o coeficiente angular da reta foi de 0,614 , enquanto que para o genótipo Asterix o coeficiente foi 0,630 . Essa diferença, de 1,4\%, provavelmente é devida à arquitetura foliar mais favorável à penetração de Rg no dossel do genótipo Asterix, a qual apresenta folhas menores e mais eretas do que o genótipo Macaca. Segundo Khurana e McLaren (1982), a interceptação de radiação pelo dossel depende do IAF e o arranjo geométrico das folhas, além de que o ângulo das folhas pode variar com o aumento do tamanho das folhas, afetando a geometria das mesmas. Mesmo assim, pode-se inferir que os dois genótipos interagem de maneira semelhante com a $\mathrm{Rg}$, indicando ser possível utilizar um mesmo modelo para estimar o Rn em cultivos com esses dois genótipos.

Os valores das estatísticas obtidas confirmam que o Rn de cultivos de batata pode ser estimado com base na Rg durante o período diurno, visto os elevados coeficientes de determinação obtidos, tanto na geração $\left(\mathrm{R}^{2}\right)$ quanto no teste dos modelos $\left(\mathrm{r}^{2}\right)$, e principalmente os baixos valores 
de RQME e altos valores de coeficientes de confiança (d). Esse resultado concorda com Fietz e Fisch (2009), que obtiveram como melhor modelo, para estimativa do Rn, aquele que considera apenas a radiação solar global. A RQME apresentou tendência de ser mais elevada para os modelos de FI-P do que de FV-O, mas ficou abaixo de 0,87 e 0,73 , respectivamente (TAB. 1). Os resultados do teste dos modelos são próximos dos observados por Sentelhas e Nascimento (2003) que observaram para o saldo de radiação estimado a partir da radiação solar global um erro médio absoluto de $0,74 \mathrm{MJ} \mathrm{m}^{-2} \mathrm{dia}^{-1}$. A utilização de modelos separados por época ou não, dependerá da maior ou menor precisão requerida.

Esses resultados têm elevada relevância prática, visto que nas estações meteorológicas dos sistemas dos serviços oficiais de meteorologia e nas estações de sistemas operacionais de agrometeorologia o registro de $\mathrm{Rn}$ em geral não é feito (SENTELHAS; NASCIMENTO, 2003), devido ao alto custo de aquisição e manutenção de saldo radiômetros.

\section{Conclusões}

1. A densidade de fluxo de energia do Rn em dosséis de batata pode ser estimada, com boa precisão, por meio da utilização da densidade de fluxo de Rg medida nas estações automáticas;

2. A média da relação $\mathrm{Rn} \mathrm{Rg}^{-1}$ em dosséis de batata varia em cerca de $5 \%$ com a época de cultivo, principalmente devido ao maior índice de área foliar dos cultivos de FIprimavera em relação aos do FV-outono;

3. Para a estimativa do $\mathrm{Rn}$ em dosséis de batata, dependendo da precisão exigida, pode ser utilizado um modelo geral único, independendo da condição de umidade na camada superficial do solo, da época do ano e do genótipo utilizado.

\section{Referências}

ABRAHA, M. G.; SAVAGE, M. J. Comparison of estimates of daily solar radiation from air temperature range for application in crop simulations. Agricultural and Forest Meteorology, v. 148, n. 03, p. 401-416, 2008.

ARRAES, F. D. D. et al. Identificação dos íons determinantes da condutividade elétrica nas águas superficiais da bacia do Cuva, Ceará. Revista Ciência Agronômica, v. 40, n. 03, p. 346-355, 2009.

AZEVEDO, P. V. et al. Balanço de radiação sobre culturas irrigadas no semi-árido do Nordeste do Brasil. Revista Brasileira de Meteorologia, v. 05, n. 01, p. 403-410, 1990.
BISOGNIN, D. A. Recomendações técnicas para o cultivo da batata no Rio Grande do Sul e Santa Catarina. 1. ed. Santa Maria: UFSM, 1996. 64p.

BISOGNIN, D. A. et al. Desenvolvimento e rendimento de clones de batata na primavera e no outono. Pesquisa Agropecuária Brasileira, v. 43, n. 06, p. 699-705, 2008.

COSTA, C. A. G. et al. Análise da influência vegetacional na altimetria dos dados SRTM em bacias hidrográficas no semiárido. Revista Ciência Agronômica, v. 41, n. 02, p. 222-230, 2010.

DANTAS, A. A. D. et al. Estimativa da radiação solar global para a região de Lavras, MG. Ciência Agrotécnica, v. 27, n. 06, p. 1260-1263, 2003.

EMBRAPA. Centro Nacional e Pesquisa em Solos. Sistema Brasileiro de Classificação de Solos. Rio de Janeiro: EmbrapaSolos, 2006. 306p.

FIETZ, C. R.; FISCH, G. F. Avaliação de modelos de estimativa do saldo de radiação e do método de Priestley-Taylor para a região de Dourados, MS. Revista Brasileira de Engenharia Agrícola e Ambiental, v. 13, n. 04, p. 449-453, 2009.

HELDWEIN, A. B.; STRECK, N. A.; BISOGNIN, D. A. Batata. In: MONTEIRO, J. E. B. A. Agrometeorologia dos Cultivos O Fator Meteorológico na Produção Agrícola. Brasília: INMET, 2009. p. 93-108.

HELDWEIN, A. B.; BURIOL, G. A.; STRECK, N. A. O Clima de Santa Maria. Revista Ciência Ambiente, v. 38, p. 43-58, 2010.

IBGE. Sistema IBGE de Recuperação Automática - SIDRA. Disponível em: http://www.sidra.ibge.gov.br/bda/agric/default. asp? $\mathrm{t}=4 \& \mathrm{z}=\mathrm{t} \& \mathrm{o}=11 \& \mathrm{u} 1=1 \& \mathrm{u} 2=1 \& \mathrm{u} 3=1 \& \mathrm{u} 5=1 \& \mathrm{u} 6=1 \& \mathrm{u} 4=1$. Acesso em: 28 de janeiro de 2009.

IRMAK, S.; ODHIAMBO, L. O.; MUTIIBWA, D. Evaluation the impact of daily net radiation models on grass and alfalfareference evapotranspiration using Penman-Monteith equation in a sub-humid and semi-arid climate. Journal of irrigation and drainage engineering, v. 130, n. 02, p 59-72, 2011.

JACOBS, A. F. G; PUL, W. A .J. VAN. Seasonal changes in the albedo of a maize crop during two seasons. Agricultural and Forest Meteorology, v. 49, n. 04, p. 351-360, 1990.

KASHIAP,P.S.; PANDA, R. K. Evaluation of evapotranspiration estimation methods and development of crop-coefficients for potato crop in a sub-umid region. Agricultural Water Managemnet, v. 50, n. 01, p. 9-25, 2001.

KHURANA, S. C.; MCLAREN, J. S. The influence of leaf area, light interception and season on potato growth and yield. Potato Research, v. 25, n. 04, p. 329-342, 1982.

LIMA, J. R. de S. et al. Balanço de energia em um solo cultivado com feijão caupi no brejo paraibano. Revista Brasileira de Engenharia Agrícola e Ambiental, v. 09, n. 04, p. 527-534, 2005.

MONTEITH, J. L. Validity of the correlation between intercepted radiation and biomass. Agriculture and Forest Meteorology, v. 68, p. 220-231, 1994. 
MONTEITH, J. L.; UNSWORTH, M. H. Principles of Environmental Physics. 2.ed. London: Edward Arnold, 1990. 291p.

NEVES, L. O. et al. Balanço de energia em uma cultura de feijão caupi (Vigna unguiculata L.) no estado do Pará. Revista Brasileira de Agrometeorologia, v. 16, n. 01, p. 21-30, 2008.

OLIVEIRA, C. A. S. Potato crop growth as affected by nitrogen and plant density. Pesquisa Agropecuária Brasileira, v. 35, n. 05, p. 939-950, 2000.

PEZZOPANE, J. R. M.; PEDRO JÚNIOR, M.J. Balanço de energia em vinhedo de "niágara rosada". Bragantia, v. 62, n. 01, p. 155-161, 2003.

PEZZOPANE, J. R. M. et al. Radiação solar e saldo de radiação em cultivo de café a pleno sol e consorciado com banana "prata anã”. Bragantia, v. 64, n. 03, p. 485-497, 2005.
SAMANI, Z. et al. Estimating daily net radiation over vegetation canopy through remote sensing and climatic data. Journal of irrigation and drainage ingineering, $v .133, \mathrm{n}$. 04, p. 291-297, 2007.

SENTELHAS, P. C.; NASCIMENTO, A. L. C. Variação sazonal da relação entre o saldo de radiação e a irradiância solar global. Revista Brasileira de Meteorologia, v. 18, n. 01, p. 71-77, 2003.

SILVA, L. D. B. et al.. Relações do saldo de radiação em grama batatais e capim tanzânia com a radiação solar global em Piracicaba, SP. Revista Brasileira de Agrometeorologia, v. 15, n. 03, p. 250-256, 2007.

TEIXEIRA, A. H. C. Avaliação dos componentes do balanço de energia durante o primeiro ano de cultura da banana. Revista Brasileira de Engenharia Agrícola e Ambiental, v. 5, n. 01, p. 28-32, 2001.

TYAGI, N. K. et al. Determination of evapotranspiration and crop coefficients of rice and sunflower with lysimeter. Agricultural Water Management, v. 45, n. 01, p. 41-54, 2000. 